\title{
The Effect of CRM System on Sales Man- agement Control: A Case Study
}

\author{
Liang Li Ji-Ye Mao \\ School of Business, Renmin University of China, Beijing, P. R. China
}

\begin{abstract}
Whereas prior research has paid little attention to the effect of CRM system on internal process control, this case study illustrates control-related CRM usage by investigating how effective sales management control through CRM and why. Results show that the CRM application can strengthen formal control and informal control simultaneously. These control modes are made feasible by enhanced outcome measurability, task programmability, and process visibility of sales work brought by CRM. CRM also sets the benchmark of sales ideals and serves as an effective self-management tool.
\end{abstract}

Keywords: customer relationship management, CRM system, sales management controls, organizational controls

\section{Introduction}

Firms invested in CRM systems to pursue better customer services, and expected to increase customer satisfaction and realize customer retention. CRM applications can not only enhance firm-level organizational performance [4][18], but also have impacts on the process-level performance, which include customer-related impacts and operation-related impacts [4][10]. As a typical enterprise system, a CRM system can also be expected to make information centralized, processes standardized, and employees' behaviors and outcomes more transparent. However, control-related CRM usage has received little attention in prior research. Thus, this paper sets out to investigate the following two research questions: (1) how do executives and managers exercise effective sales management control through a CRM system, and (2) why CRM system can be used as a tool for sales management control? A case study was conducted to address these research questions.

The rest of this paper is organized as follows. First, we review organizational control theory as the theoretical perspective to orient our research. We then describe the case context and explain our choice of research method. Next, we analyze how and why the control-related CRM usage is exercised and the results of data analysis are presented. Lastly, we discuss the key findings and implications of this work.

\section{Theoretical Perspective: Organiza- tional Control Theory}

Control is viewed in a behavioral sense [2][12], as formal and informal processes of negotiation between organizational members (e.g., managers and employees) "in which various strategies are developed... to produce particular outcomes" [3]. This view of control implies that the controller employs certain devices, or control mechanisms, to ensure proper controllee behavior [2][12]. In general, there are two types of control modes, i.e., formal controls and informal controls [5][8]. Formal controls are considered written, management-initiated mechan- 
isms and informal controls unwritten, worker-initiated mechanisms [9].

\subsection{Formal and Informal Controls}

In formal controls, the controller influences the controllee's behavior and activities by establishing a set of procedures to monitor, direct, evaluate, and reward the controllee [1][5]. There are two types of formal control modes: outcome control and behavior control [5][16]. In outcome control, the controller focuses on whether interim or final outcomes are achieved but does not consider its process [8]. The controller sets performance metrics and evaluates the results to rewards the controllee for meeting those goals [8][9]. In behavior control, the focus is on the means to achieve desired ends. The controller prescribes specific rules and procedures, monitors and evaluates the controllee's behavior, and rewards the controllee based on the extent to which it follows stated procedures.

Informal controls emphasize more on social or "people" factors [5], including clan control and self-control. Clan control is implemented when the controller promulgates shared experiences, values, and beliefs within a group of individuals [11]. In self-control, the controllee is intrinsically motivated and sets task goals and procedures for its own behavior [11]. However, the controller can encourage or motivate the controllee to help enhance its ability to exercise control internally [2].

\subsection{Antecedents of Organizational Controls}

Prior researchers have identified key factors influencing the choice of control [1][13]. Organizational factors, such as task characteristics, knowledge of the transformation process, and the size of the strategic business unit (SBU), are the main influencing variables that determine an organization's choice among formal and informal controls [1][5][8][13]. Task characteristics include behavior observability, outcome measurability, and task programmability [2][5][11][16]. If the appropriate behaviors of a task can be specified in advance and the controller has ability to gather information about the controllee's behavior, behavior control is more likely to use to ensure the prescribed task process is followed. If the controller has ability to specify and track desired the outcomes, on the other hand, outcome control is more likely to exercise to evaluate the controllee's task performance $[2][5][11][12]$.

\section{Research Methods}

We employed a case study method to investigate the effect of CRM on sales management control. The case study method fits our objective well for several reasons. Firstly, we focus on how and why the control-related CRM usage is exercised, and the case study method is suitable for "how" or "why" questions [21]. Secondly, we found little research on the topic of control-related CRM usage, in which case the case study method is particularly appropriate [6]. Lastly, this research was carried out in Chinese management context, so it is necessary to consider the fitness between the context and the phenomena [19]. Such consideration is consistent with the logic of the case study design [20][21].

\subsection{Research Setting}

We carried out our investigation in Nodes Company (hereinafter referred to as Nodes), which is a small- to mediumsized Chinese IT firm founded in 1996. It provided wireless network products and total solutions for enterprise-class customers, and its business covered distribution of hardware products, system inte- 
gration, and software development. As the development and wide application of wireless network technology, Nodes has gained rapid increasing sales at an annual rate of $50 \%$ from 1999 to 2004 . Its size is also enlarged from about 10 employees in 1999 to more than 60 in 2004. In addition to the headquarters in Beijing with four divisions, three offices were set up in Tianjin, Shanghai and Guangzhou.

Prior to the CRM use, Nodes' sales representatives used Excel spreadsheets and paper and pens to manage customers' information. These data scattered among sales reps' personal computers and notebooks, so gradually became personal assets rather than organizational resources, which resulted in the loss of customer resources. Nodes' executives lacked means to monitor those who worked in out of town offices. Therefore, Nodes decided to implement a CRM system at the end of 2005. After several months' implementation and three years' actual use, the CRM system proved to be effective in improving Nodes' internal management ability.

\subsection{Data Collection}

We collected data from two main sources: archival documents and in-depth interviews. Before the arrangement of interviews, we read an internal document written by a vice general manager of Nodes, who was the leader of the CRM project. In addition, we conducted two rounds of in-depth interviews in 2009. We interviewed 8 informants, including the general manager, the vice general manager, two business managers and four business reps, who were all CRM users. Each interview lasted between one hour and one hour and a half. The interviews were conducted by both authors together. The interviews were recorded and transcribed for analysis.

\subsection{Data Analysis}

Our data analysis was largely based on coding and comparative analysis [15]. Firstly, we identified sales management control mechanisms of pre- and postCRM implementation respectively. Then, we compared these control mechanisms and found the effect of CRM on the evolution of such mechanisms. Lastly, we linked all the identified concepts and explained the phenomenon of controlrelated CRM usage. During this process, organizational control theory was regarded as the framework to steer our analyzing direction.

Step 1: Identifying sales management control mechanisms of pre- and post$C R M$ implementation respectively. The first author marked off all the transcripts related to sales control activities before and after CRM implementation, which helped us divide the data into meaningful chunks of units for analysis [15]. Our coding strategy was between the a priori and inductive approaches [15]. The organizational control theory created a general accounting scheme for codes that was not CRM usage specific, but pointed to the general domains in which codes could be developed inductively. The second author cross-checked the coding results and discussed with the first author until they reached the agreement.

Step 2: Identifying the effect of CRM on the evolution of sales management control mechanisms. We compared the four control modes and corresponding control mechanisms and identified their similarities and differences. Based on the approaches of Glick et al. (1990) [7] and Romanelli and Tushman (1994) [17], we identified the evolution of control mechanisms as to (1) whether a new control mechanism was established, (2) whether an initial control mechanism was discarded, and (3) whether a control mechanism was retained across CRM implementation and it was augmented or lessened in intensity. 
Step 3: Drawing conclusions. We interpreted the relationships between the identified control mechanisms and the effect of CRM on their evolution, which helped us make sense of the phenomenon of control-related CRM usage.

\section{Results}

This section presents the results of data analysis. First, along with the CRM system, Nodes introduced multiple CRMbased control mechanisms, which simultaneously strengthened all four modes of control. Second, CRM changed the antecedents for exercising management control, such as outcome measurability, task programmability, and process visibility of sales work. It also set the benchmark of sales ideals and serves as an effective self-management tool.

\subsection{Control Mechanisms Prior to CRM}

Previously, the four modes of control were in use to various degrees. First, one of the main outcome control mechanisms was to set performance requirements for sales reps, such as sales quantity and net profits. Nodes also collected the outcome information through monthly or quarterly sales reports, and executives and managers were difficult to reach the details of each sales rep's work results. Second, behavior control relied upon mechanisms such as Excel spreadsheets, weekly meetings, and direct observations to collect information about sales reps' behaviors. However, there were also some challenges. For example, when sales reps used Excel spreadsheets to record information, the extent of information details rather depended on each sales rep's personal factors such as business skills, the level of computer ability, and the degree of self-conscious. Important customer and project information may be omitted by inexperienced sales reps. Third, clan control was primarily based on oral communication. On one hand, managers made requirements to sales reps about work procedure such as the frequency of visiting customers. Lastly, self-control was via sales people's use of spreadsheets. However, it was difficult to update customer data. Moreover, it was really a huge amount of work, as there were more than two thousand contacts to be managed for some senior sales reps.

\subsection{Control Mechanisms through CRM}

\subsubsection{CRM-based Outcome Control}

Nodes used CRM to strengthen performance management. The mechanisms included performance requirements, sales reports and CRM records. Based on CRM, the performance of business reps was not only reflected by the signed contracts, but also decomposed into the interim results of every stage during sales process, such as the amount of sales clues and sales opportunities and their upgrading status. These interim results were regarded as another aspect of metrics to assess employees' performance. The general manager said:

"After the application of such platform [CRM], we can quantify much more things when we evaluate the sales reps' performance. In every stage, such as every month, we will require them to establish a certain number of new sales clues, or we will examine the upgrading status of sales opportunities. If they meet with some difficulties, managers can extract related data from CRM, which is also very useful for our administration."

In addition, executives and managers of Nodes also evaluated sales reps' per- 
formance through CRM records. Managers could have a general impression and judgment on employees' work status and project progression. A sales manager said:

"If there are only few new customers and no upgrading of sales opportunities in recent weeks, and I don't know what you have been doing every day, ... and if all of them are in such status, I will doubt whether there are some problems with our marketing and we all have few sales opportunities and calls per se. If one employee is in such status and others can do well, whether there are some problems with his/her work status?"

\subsubsection{CRM-based Behavior Control}

In Nodes' CRM application for sales management control, the core control activities were those exercised on sales process. Before the implementation of CRM, sales projects in Nodes were not clearly divided into different stages. After the implementation, however, sales reps were required to follow the embedded rules and procedures in CRM to promote the project. They started from sales clues, then identified the sales opportunities in them, then promoted these opportunities until the contracts were signed. Such sales stages were totally consistent with the embedded procedures in CRM. A sales rep said:

"Now some initial business processes are regulated. The interaction with customers, for example, is divided into several sub-stages. Sometimes we start with the initial contact stage, then the scheme design stage, the quote stage, the customers' evaluation stage, the contract signing stage, and so on. We deal with customers by multiple stages. The current stages of every customer can be reflected in CRM clearly. We also take notes after the stage, which provide lots of references for our business."

Nodes also regarded employees' CRM records as an information collecting mechanism to monitor their behavior regularly. On one hand, executives were fully aware of the importance of data quality in CRM, so they required that, as long as employees could access to Internet, they should update customer information and input "actions" into CRM in time. On the other hand, executives and managers had higher authorities in CRM than business reps, so they could view the records of their subordinates and pay attention to subordinates' daily work in real time. A department manager said, for example, she usually kept her CRM account alive when she was at work. Besides her own work, she also viewed the newly updated records of her subordinates now and again. All the conditions of her subordinates were in her eyes, so as to avoid that some conditions were concealed intentionally or unintentionally.

Another CRM-based behavior control mechanism was that executives and managers examined and evaluated sales reps' behaviors through weekly meetings. At meetings, managers projected everyone's CRM account onto screen to display his/her records. Based on the CRM projection, business reps reported how they established the new sales clues and upgraded sales opportunities, and then managers gave out their evaluations and feedbacks.

Once executives and managers found that it was not consistent between employees' actual working process and specified procedures, or they found that employees didn't meet the prescribed performance, they would carry out management interventions through CRM. When 
sales reps met with some problems during work, managers would know what kind of help they need and direct and assist them in proper time, such as to help them differentiate customers based on the importance, or guide them to do something to promote project mostly at key stages.

A service manager said:

"I can help them [subordinates] for some work. I can know what kind of help they need and what kind information they want through CRM. Sometimes they are not willing to communicate with me face-toface too frequently, and maybe they can solve some problems by themselves, but they may need much more time than under my assistance."

Moreover, when facing the important customers and projects, executives and managers used CRM to exert sales project management by assigning work to employees in different departments or different positions to establish temporary teams. Such assignment coordinated the human resources, capitals, and other resources related to the project efficiently.

\subsubsection{CRM-based Clan Control}

The rules, procedures, and related concepts embedded in CRM acted as "educating" and "training" employees. CRM brought new sales ideas into Nodes so that executives could control employees in ideals. Before the implementation of CRM, there were no concepts such as "sales actions", "sales clues", or "sales opportunities". Business reps carried out projects based on their own experience. Through the application of CRM, these concepts not only were widely used in the system, but also became their jargons in daily work. The general manager said:

"We didn't have such concepts as 'actions' and some notions about sales process. ...
Before the implementation of CRM, we might promote projects only by calling and visiting customers. Now we start with sales clues, and then discover more opportunities. One customer may have several opportunities, and we upgrading them step by step following these concepts."

Another concept that CRM brought was how to deal with customers in business, or the notion of "relationship marketing". Based on the configuration of CRM, sales reps collected some customers' individual information, such as their hobbies, their families, and their kids. Such information was used as topics to strengthen their relationships in informal communications.

Nodes promoted employees' shared sales ideals through brainstorming during CRM-based weekly meetings as well. After sales reps projected their CRM accounts into screen to display the current status and problems, department manager would organize other team members to discuss mutually and analyze what to do in the next step. Through such brainstorming mechanism, Nodes strengthened the atmosphere of mutual advice-giving. At the same time, employees could also feel peer pressure. If the CRM records of his colleagues were in great detail, and they had built lots of new sales clues and opportunities, while the CRM records of his own were simple and had less opportunities, he would push himself to work harder to exhibit better performance in next weekly meetings.

CRM also facilitated the coordination among employees. Sometimes Nodes' different departments or different business reps in a department dealt with the same customers, so the sales opportunities might come from not only the sales reps, but also the service reps, engineers, or employees of other departments. 
Nodes shared important information between these fellows in CRM conveniently to promote sales projects together. Through such information sharing mechanism, Nodes also unified some business rules, such as payment terms and service response time, to avoid customers' negative impression brought by the inconsistence business rules between different departments.

\subsubsection{CRM-based Self-Control}

The sales rep is a job position which needs high level of self management. CRM provides effective self management tools for sales reps to enable better selfcontrol through the mechanisms of work schedules and knowledge base. Using CRM, employees could set their own work schedules based on the information combination of "customers" and "importance and emergency of tasks". They arranged their timetable to customers and tasks with variant level of importance and emergency, so as to concentrate on the most beneficial customers and tasks. In their daily work, employees first finished tasks which were both important and emergent, such as the bidding invitation and service request. Then they focused on tasks which were important but not so emergent, such as relationship maintenance of strategic customers.

Besides the task arrangement, employees also set task reminders in CRM work schedules, urging themselves to complete planed tasks before deadlines. During our interviews, a sales rep gave us an example which had made her embarrassed:

"Sometime I spent three and a half days of a week working in the field. The previous Friday one customer made an order, requesting seven days delivery time. That week passed quickly. In the following week, my sales assistant and I were just at that customer's office. Suddenly she reminded me that it was that day to deliver the equipment. I was getting into muddle right off. ... Then and there I shot my thigh and said with embarrassedly: 'Whoops! I would have input that information into CRM!',"

Furthermore, employees could learn the experience of their predecessors and colleagues by themselves through the knowledge management function of CRM. It was especially obvious for new staffs. When employees met problems or puzzles in their work, they would first look up related experience-summarizing articles in the knowledge database. If problems still couldn't be solved, they then sought help from managers. On the other hand, the self-learning also included the acquainting with customers and projects. When new staffs took over a project, they could look through the detailed information about what had been done by their predecessors, what stage the project was, and who were the key contacts. Such information was valuable for those inexperienced new staffs, and their skills were promoted by such selflearning.

\begin{tabular}{|c|c|}
\hline $\begin{array}{c}\text { Control } \\
\text { Mechanism }\end{array}$ & Examples \\
\hline \multicolumn{2}{|c|}{ Outcome Control } \\
\hline $\begin{array}{l}\text { Performance } \\
\text { require- } \\
\text { ments }\end{array}$ & $\begin{array}{l}\text { Performance of business reps } \\
\text { was not only reflected by } \\
\text { the signed contracts, but al- } \\
\text { so decomposed into the } \\
\text { CRM-based interim results } \\
\text { of each sales process stage. }\end{array}$ \\
\hline $\begin{array}{l}\text { CRM } \\
\text { records }\end{array}$ & $\begin{array}{l}\text { Executives and managers eva- } \\
\text { luated sales reps' perfor- } \\
\text { mance and work status } \\
\text { through CRM records. }\end{array}$ \\
\hline \multicolumn{2}{|c|}{ Behavior Control } \\
\hline $\begin{array}{l}\text { Embedded } \\
\text { rules and } \\
\text { proce- } \\
\text { dures in }\end{array}$ & $\begin{array}{l}\text { Each sales project was di- } \\
\text { vided into different stages } \\
\text { through the embedded rules } \\
\text { and procedures in CRM, }\end{array}$ \\
\hline
\end{tabular}




\begin{tabular}{|c|c|}
\hline CRM & $\begin{array}{l}\text { which were prescribed as } \\
\text { the standard process. }\end{array}$ \\
\hline $\begin{array}{l}\text { CRM } \\
\text { records }\end{array}$ & $\begin{array}{l}\text { Managers viewed sales reps' } \\
\text { CRM records in real time } \\
\text { to monitor their work activ- } \\
\text { ities. }\end{array}$ \\
\hline $\begin{array}{l}\text { Weekly } \\
\text { meetings }\end{array}$ & $\begin{array}{l}\text { Business reps were required } \\
\text { to exhibit and report work } \\
\text { progress at weekly meet- } \\
\text { ings with CRM information } \\
\text { projecting on the screen. }\end{array}$ \\
\hline $\begin{array}{l}\text { Management } \\
\text { interven- } \\
\text { tions }\end{array}$ & $\begin{array}{l}\text { Executives and managers di- } \\
\text { rected or assisted sales reps } \\
\text { in their work, and coordi- } \\
\text { nated their work through } \\
\text { CRM-based management } \\
\text { interventions. }\end{array}$ \\
\hline \multicolumn{2}{|l|}{ Clan Control } \\
\hline $\begin{array}{l}\text { Embedded } \\
\text { rules and } \\
\text { proce- } \\
\text { dures in } \\
\text { CRM }\end{array}$ & $\begin{array}{l}\text { The embedded rules and pro- } \\
\text { cedures in CRM introduced } \\
\text { new sales ideals to sales } \\
\text { reps, especially the notion } \\
\text { of relationship marketing. }\end{array}$ \\
\hline $\begin{array}{l}\text { Weekly } \\
\text { meetings }\end{array}$ & $\begin{array}{l}\text { Shared sales ideals were pro- } \\
\text { moted and atmosphere of } \\
\text { mutual advice-giving was } \\
\text { strengthened through } \\
\text { CRM-based weekly meet- } \\
\text { ings. }\end{array}$ \\
\hline $\begin{array}{l}\text { Information } \\
\text { sharing }\end{array}$ & $\begin{array}{l}\text { Team members relied on and } \\
\text { coordinated with each other } \\
\text { more closely through }\end{array}$ \\
\hline \multicolumn{2}{|l|}{ Self-Control } \\
\hline $\begin{array}{l}\text { Work sche- } \\
\text { dules }\end{array}$ & $\begin{array}{l}\text { Sales reps arranged their own } \\
\text { timetable with variant level } \\
\text { of importance and emer- } \\
\text { gency and set task remind- } \\
\text { ers through CRM-based } \\
\text { work schedules. }\end{array}$ \\
\hline $\begin{array}{l}\text { Knowledge } \\
\text { base }\end{array}$ & $\begin{array}{l}\text { Sales reps learned the expe- } \\
\text { rience of their predecessors } \\
\text { and colleagues through the } \\
\text { knowledge base of CRM. }\end{array}$ \\
\hline
\end{tabular}

Table 1: Control Mechanisms Exercised through CRM.

\subsection{Why CRM Strengthened Sales Management Control}

The results of data analysis reveal that as a typical enterprise system, CRM changed the antecedents for exercising management control. In other words, CRM enhanced outcome measurability, task programmability, and process visibility of sales work. It also set the benchmark of sales ideals and served as an effective self-management tool.

Sales Outcome Control. CRM strengthened outcome control by enhancing the performance measurability of sale reps' work. Firstly, executives and managers could decompose performance metrics. Before the implementation of CRM, they could only prescribe the final performance results. While through CRM, they could specify interim results and more detailed performance metrics. Secondly, executives and managers could measure sale reps' performance more precisely. The measurement of some performance metrics, which had been difficult to implement initially, such as the amount of calls to customers, were enabled by CRM in the form of "actions". Thirdly, executives and managers could measure sales interim results more flexibly. The frequency that they measured sales reps' interim results was shortened from monthly or even quarterly to at any time. They even could view the CRM records when they were at home after work.

Sales Behavior Control. CRM strengthened behavior control by enhancing the task programmability and process visibility of sale reps' work. The task programmability was enhanced because the embedded rules and procedures in CRM provided sales reps a standard process to follow and each sales project was clearly divided into different stages, just as one sales rep said: "Now the sales work [in CRM] is just like software installment. Next step, next step, you proceed following the next step and it will be OK."

The process visibility was enhanced for two reasons. On one hand, executives and managers could observe sales reps behavior through CRM records in real time. Secondly, executives and managers could 
observe sales reps behavior through CRM records more completely.

Sales Clan Control. CRM strengthened clan control by unifying the sales ideals among team members and enhancing the extent to which they relied on and coordinated with each other. CRM set benchmark of sales ideals for sales reps and introduced new business concepts such as "sales actions", "sales clues", or "sales opportunities". Second, CRM enhanced the process visibility for team members so as to facilitate team coordination through information sharing.

Sales Self-Control. CRM strengthened self-control for it is an effective selfmanagement tool. Armed with CRM, sales reps can better arrange his/her own work and their professional skills are also improved.

\begin{tabular}{|c|c|}
\hline & The Effect of CRM \\
\hline \multirow[t]{4}{*}{$\begin{array}{l}\text { Outcome } \\
\text { Control }\end{array}$} & $\begin{array}{l}\text { Enhancing sales outcome } \\
\text { measurability }\end{array}$ \\
\hline & $\begin{array}{l}\text { Performance me- } \\
\text { trics could be decomposed }\end{array}$ \\
\hline & $\begin{array}{l}\text { Performance could } \\
\text { be measured more precise- } \\
\text { ly }\end{array}$ \\
\hline & $\begin{array}{l}\text { - Interim results } \\
\text { could be measured more } \\
\text { flexibly }\end{array}$ \\
\hline \multirow[t]{4}{*}{$\begin{array}{l}\text { Behavior } \\
\text { Control }\end{array}$} & $\begin{array}{l}\text { Enhancing sales task pro- } \\
\text { grammability }\end{array}$ \\
\hline & $\begin{array}{l}\text { Enhancing sales process visi- } \\
\text { bility (for managers) }\end{array}$ \\
\hline & $\begin{array}{l}\text { Behavior could be } \\
\text { observed in real time }\end{array}$ \\
\hline & $\begin{array}{l}\text { Behavior could be } \\
\text { observed more completely }\end{array}$ \\
\hline \multirow[t]{2}{*}{ Clan Control } & $\begin{array}{l}\text { Setting the benchmark of } \\
\text { sales ideals }\end{array}$ \\
\hline & $\begin{array}{l}\text { Enhancing sales process visi- } \\
\text { bility }\end{array}$ \\
\hline Self-Control & $\begin{array}{l}\text { Serving as a more effective } \\
\text { self-management tool }\end{array}$ \\
\hline
\end{tabular}

Table 2: Why CRM Strengthened Control.

\section{Discussion}

\subsection{The Exercise of CRM-based Sales Management Control}

Formal Control. The improvement of formal controls is the major aspect of control-related CRM usage. Management established CRM-based regulations and decomposed performance measures for sales reps. Sales reps' activities were under closer monitoring, and timely intervene became possible when needed. Moreover, management prescribed more specific rules and procedures, and set expected goals. They also monitor whether sales reps' behavior meet the specified rules and procedures, and evaluate whether sales reps' outcomes meet the expected goals.

Informal Control. Through the introduction of CRM, Nodes strengthened work coordination by information sharing and brainstorming, as well as introduced new managerial concepts and the notion of relationship marketing. These activities reduced the differences of the way managers and team members behave and of the beliefs between managers and team members. Sales reps deepened their understanding to sales work and improved their business skills. These control activities are mostly instituted by project teams or departments and lead to sales reps' strong commitment to Nodes. On the other hand, the CRM-based self-control is reflected in the self-management on their jobs. They could arrange their tasks according to the extent of importance and emergency. They also learned their predecessors' work experience through the knowledge function of CRM, leading to the improvement of professional skills.

\subsection{Why CRM Strengthened Control}

CRM changed the antecedents of sales management control. Control is made feasible by the enhanced outcome measu- 
rability, task programmability, and process visibility of brought by CRM. It created a series of conditions for some control modes which had been difficult to exercise, and the CRM-based control activities were more effective. At the same time, CRM provides a benchmark of "best practice" and executives can use it to promote skills of sales reps.

Control-related CRM usage arose in a organizational context, featuring low management maturity, small enterprise size, and sales reps' low skill levels. Potential benefits brought by CRM-based control could be particular salient in such contexts. Prior research has indicated that, in the Chinese business context, information is fundamentally a personal asset rather than an organizational resource [14]. The initial intention of executives to implement CRM was to exercise better sales management control, and CRM fulfill their anticipation in practice. It also supports the notion that the IT investment in the Chinese business culture has typically stemmed from a desire to monitor and control the basic operations in an expanding business [14].

\subsection{Implications and Limitations}

A key contribution of our research is that we illustrate an under studied phenomenon of CRM usage, which extends the understanding of the CRM impact on firm performance. We believe that control-related CRM usage is an important dimension of the CRM impact on firm performance, especially in Chinese business context. We propose that in nowadays Chinese firms, the CRM system pays back greatly in sales management controls, even greater than the external benefits gained from customer service. Moreover, we deepen the understanding of salesforce control in prior research. We believe that the sales technologies, represented by the CRM system, are ef- fective tools to better exercise controls on sales reps.

There are also several limitations in this study. First, this study is to illustrate an unexpected phenomenon of CRM usage in prior research, so it may be context-specific. Second, Nodes is a smallsized firm, which may limit our data collection and the generality of our research findings. Third, limited by the space limit, we are not able to discuss the consequences of CRM-based management control. Particularly, improper controls may cause some negative results, which should be examined in more contexts.

\section{Conclusions}

This study illustrates the phenomenon of control-related CRM usage in the Chinese business context, and tries to answer two questions that how and why effective sales management control was exerted through CRM. As a typical enterprise system, CRM changes the antecedents for exercising sales management control and helps to provide more effective control mechanisms. Our findings have important implications for future research and practice, although it is important to examine the results in other research contexts. Moreover, it would also be interesting to evaluate in future research to what extent the findings can help understand CRM impacts in general.

\section{Acknowledgement}

This research was funded by the Natural Science Foundation of China (70888001) and Graduate Science Research Foundation of Renmin University of China (10XNG030).

\section{References}

[1] E. Anderson and R. Oliver, "Perspectives on Behavior-Based Versus Out- 
come-Based Salesforce Control Systems," Journal of Marketing, 51(4), pp. 76-88, 1987.

[2] V. Choudhury, R. Sabherwal, "Portfolios of Control in Outsourced Software Development Projects," Information Systems Research, 14(3), pp. 291-314, 2003.

[3] R. Coombs, D. Knights, and H.C. Willmott, "Culture, Control and Competition: Towards a Conceptual Framework for the Study of Information Technology in Organizations," Organization Studies, 13(1), pp. 5172, 1992.

[4] S. Dong and K. Zhu, "The Business Value of CRM Systems: A ResourceBased Perspective," Proceedings of the 41st Annual Hawaii International Conference on System Sciences, Big Island, HI, USA, pp. 277, 2008.

[5] K. Eisenhardt, "Control: Organizational and Economic Approaches," Management Science, 31(2), pp. 134149, 1985.

[6] K. Eisenhardt, "Building Theories from Case Study Research," Academy of Management Review, 14(4), pp. 532-550, 1989.

[7] W.H. Glick, G.P. Huber, C.C. Miller, H.D. Doty, and K.M. Sutcliffe, "Studying changes in organizational design and effectiveness: Retrospective event histories and periodic assessments," Organization Science, 1(3), pp. 293-312, 1990.

[8] B. Jaworski, "Toward a Theory of Marketing Control: Environmental Context, Control Types, and Consequences," Journal of Marketing, 52(3), pp. 23-39, 1988.

[9] B. Jaworski, V. Stathakopoulos, and H. Krishnan, "Control Combinations in Marketing: Conceptual Framework and Empirical Evidence," Journal of Marketing, 57(1), pp. 57-69, 1993.

[10] J. Karimi, T. Somers, and Y. Gupta, "Impact of Information Tech- nology Management Practices on Customer Service," Journal of Management Information Systems, 17(4), pp. 125-158, 2001.

[11] L. Kirsch, "The Management of Complex Tasks in Organizations: Controlling the Systems Development Process," Organization Science, 7(1), pp. 1-21, 1996.

[12] L. Kirsch, "Portfolios of Control Modes and IS Project Management," Information Systems Research, 8(3), pp. 215-239, 1997.

[13] M. Krafft, “An Empirical Investigation of the Antecedents of Sales Force Control Systems," Journal of Marketing, 63(3), pp. 120-134, 1999.

[14] M. Martinsons and R. Westwood, "Management Information Systems in the Chinese Business Culture: An Explanatory Theory," Information \& Management, 32(5), pp. 215-228, 1997.

[15] M.B. Miles and M. Huberman, Qualitative Data Analysis: A Sourcebook of New Methods, Sage Publications, Beverly Hills, 1994.

[16] W.G. Ouchi, "A Conceptual Framework for the Design of Organizational Control Mechanisms," Management Science, 25(9), pp. 833-848, 1979.

[17] E. Romanelli and M.L. Tushman, "Organizational Transformation as Punctuated Equilibrium: An Empirical Test," Academy of Management Journal, 37(5), pp. 1141-1166, 1994.

[18] L. Ryals, "Making Customer Relationship Management Work: The Measurement and Profitable Management of Customer Relationships," Journal of Marketing, 69(4), pp. 252261, 2005.

[19] A. Tsui, "Contextualization in Chinese Management Research," Management and Organization Review, 2(1), pp. 1-13, 2006. 
[20] R.K. Yin, "The Case Study Crisis: Some Answers," Administrative Science Quarterly, 26(1), pp. 58-65, 1981.

[21] R.K. Yin, Case Study Research: Design and Methods(3rd ed.), Sage Publications, Thousand Oaks, California, 2003. 